\title{
Lumbrokinase/paclitaxel nanoparticle complex: potential therapeutic applications in bladder
} cancer

This article was published in the following Dove Press journal: International Journal of Nanomedicine

Bo $\mathrm{Hu}^{\prime}$

Ying Yan ${ }^{2}$

Fei Tong'

Long $\mathrm{Xu}^{\prime}$

Jia Zhu'

Guangtao Xu'

Ruilin Shen'

'Department of Oncopathology, Institute of Diabetes and Urological Disease, Jiaxing Hospital of Traditional Chinese Medicine, Jiaxing University, Jiaxing, ${ }^{2}$ Department of Rehabilitation Medicine, The Third Affiliated

Hospital of Zhejiang Chinese Medical University, Hangzhou, People's

Republic of China
Correspondence: Guangtao Xu;

Ruilin Shen

Department of Oncopathology, Institute of Diabetes and Urological Disease, Jiaxing Hospital of Traditional Chinese Medicine, Jiaxing University, 118 Jiahang Road, Jiaxing 3/400I, Zhejiang,

People's Republic of China

Tel +8657383643806

Email gtxu@mail.zjxu.edu.cn; shenrImd@sina.com
Background: Lumbrokinase (LK) is an enzyme complex with antithrombotic, antioxidant, antitumor, and immunomodulatory effects. It has been extensively studied and used in clinical anti-tumor therapy. However, its half-life is short, its bioavailability is low, and its toxicity and side effects are great, which greatly limit its clinical application. Therefore, LK is often combined with other drugs (such as immune agents, hormones, or Chinese herbal medicine) to reduce its dosage and side effects and to improve its anti-tumor effects.

Methods and results: Here, we described an LK/paclitaxel (PTX) nanocarrier based on poly(ethylene glycol)- $b$-(poly(ethylenediamine L-glutamate)-g-poly( $\varepsilon$-benzyoxycarbonyl-L-lysine)$r$-poly(L-lysine)) (PEG- $b$-(PELG- $g$-(PZLL- $r$-PLL))). In the present study, LK and PTX were loaded by electrostatic and/or hydrophobic effects under mild conditions, thereby increasing the half-life and bioavailability of the drugs via the sustained release and enhancement of tumor site enrichment by the LK/PTX/PEG- $b$-(PELG- $g$-(PZLL- $r$-PLL)) complex through passive targeting. In this study, using bladder cancer cells (J82 cells) and rat bladder cancer model as the object, the structure of the nanocarrier, the relationship between drugs composition and antitumor properties were systematically studied. Conclusion: We propose that the block copolymer PEG- $b$-(PELG-g-(PZLL- $r$-PLL)) may function as a potent nanocarrier for augmenting anti-bladder cancer pharmacotherapy, with unprecedented clinical benefits.

Keywords: copolymer nanoparticles, lumbrokinase, paclitaxel, bladder cancer, microvessel density, p53, cyclin B1

\section{Introduction}

Bladder cancer is the fifth leading cause of cancer death in the USA and is the ninth most frequent cancer worldwide. ${ }^{1,2}$ At present, bladder cancer occurs in both sexes but is more frequent in men than in women. ${ }^{3,4}$ Furthermore, bladder cancer has become a primary clinical problem worldwide, and its incidence is constantly increasing. 5,6 In recent years, bladder cancer has become the primary cause of death among urinary tumors in China, and the mortality rate of bladder cancer is increasing. ${ }^{4,7}$ Bladder cancers are currently divided into two categories: superficial and muscle-invasive. ${ }^{8-11}$ Bladder cancers are often clinically superficial, and the 5-year survival rate of patients is $90 \%{ }^{12,13}$ However, the superficial bladder cancers are associated with a high recurrence rate. ${ }^{14,15}$ Moreover, $10 \%-20 \%$ of superficial bladder cancers quickly progress to muscle-invasive bladder cancers because of their aggressive nature. ${ }^{15,16}$ The 5 -year survival rate of muscle-invasive bladder cancers is $<50 \%{ }^{13}$

Traditional therapy for bladder cancers concentrates on surgery. However, the largest challenge is local recurrence after surgery. ${ }^{12,14,16}$ The current therapeutics for drugs and 
physiotherapy have revealed promising results and have thus been diffusely used in the clinic. ${ }^{17}$ Such therapeutics include PTX, a compound extracted from the bark of Taxus plants that may inhibit bladder tumor growth. ${ }^{18-20}$ Although PTX may achieve relatively acceptable effects, PTX is frequently unacceptable due to its powerful side effects. ${ }^{21}$ Therefore, combination therapy is often chosen to reduce the side effects of PTX and minimize its toxicity. Many studies have shown that LK has an important effect on anticancer efficacy. ${ }^{22}$ However, the half-life of LK is very short, and a high dose of LK can increase the severity of its side effects while improving the curative effect. ${ }^{23,24}$ The current delivery systems for LK mainly only include the maleic anhydride methylvinyl ether copolymer, which can immobilize LK to polyurethane (immobilized LK retained about 34\% of its activity) for antithrombogenicity in the artificial organ field. ${ }^{25}$ Therefore, a DDS that can strengthen the drug delivery efficacy and decrease the dose of drugs while not decreasing the anti-cancer efficacy may overcome the shortcomings of these drugs.

In the past few decades, biomedical research has focused more and more on DDS research. ${ }^{26}$ A variety of nanocarriers have been widely developed and used, for example, poly(D, L-lactide)- $b$-methoxy poly(ethylene glycol) (PLA-PEG) ${ }^{27}$ and layer-by-layer microcarriers, ${ }^{28}$ which loads the chemicals or protein drugs with the same chemical property (oppositely charged bio-polyelectrolytes). However, carriers capable of carrying two different chemical properties at the same time are rare.

Here, we introduce poly(ethylene glycol)- $b$-(poly (ethylenediamine L-glutamate)-g-poly( $\varepsilon$-benzyoxycarbonyl-Llysine)-r-poly(L-lysine)) (PEG- $b$-(PELG- $g$-(PZLL- $r$-PLL))) as potential LK and PTX co-carriers. The synthesis of the PEG- $b$-(PELG- $g$-(PZLL- $r$-PLL)) polymers as described previously. ${ }^{29-33}$ The negatively charged LK (the isoelectric point is 4.61) combines with a positively charged PLL brush block through electrostatic interactions, and hydrophobic PTX combines with PZLL through hydrophobic interaction at pH 7.4. The loaded LK and PTX ensure sustained release, which can improve the protective effect and bioactivity of each drug. The loading capacities of LK and PTX were chosen through their in vitro release. In an in vivo study, we assess the sustained pharmacological function of the LK/PTX/PEG$b$-(PELG-g-(PZLL- $r$-PLL)) in the restraining bladder cancer in comparison with free LK and PTX as the control.

\section{Materials and methods}

\section{Materials}

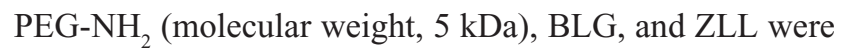
purchased from Aladdin (Shanghai, China). LK was purchased from Yuanye BioTech (Shanghai, China). PTX was purchased from Sanwei Pharmacy (Shanghai, China). J82 cells were purchased from Suer (Shanghai, China). MNU and other reagents were purchased from Sigma-Aldrich (Shanghai, China).

\section{Synthesis of PEG-b-(PELG-g-(PZLL-r- PLL))}

PEG- $b$-(PELG- $g$-(PZLL-r-PLL)) was synthesized according to our previous method. ${ }^{29-33}$ Briefly, PEG- $b$-PBLG was first synthesized by the ring-opening polymerization of BLG-NCA with PEG-NH $\mathrm{H}_{2}$ in the presence of DMF. PEG- $b$-PELG was then obtained by the aminolysis with ethylenediamine from PEG- $b$-PBLG. PEG- $b$-PELG was used as the macroinitiator to initiate the ring-opening polymerization of ZLL-NCA to obtain PEG- $b$-(PELG- $g$-PZLL). PEG- $b$-(PELG- $g$-(PZLL- $r$ PLL)) was finally yielded via the partial deprotection of the benzyl groups in PEG- $b$-(PELG- $g$-PZLL) in the presence of hydrogen bromide, trifluoroacetic acid $\left(\mathrm{CF}_{3} \mathrm{COOH}\right)$, and acetic acid $\left(\mathrm{CH}_{3} \mathrm{COOH}\right)$. Purification of the synthesized copolymers above was performed as previously described. ${ }^{29,33}$ The reaction mixtures above were purified by stirring and dialyzing at $40^{\circ} \mathrm{C}$ for different times (Table 1) and obtained by freeze-drying using a vacuum freeze-dryer (SYHX, Beijing, China) and then characterized by proton ${ }^{1} \mathrm{H}$ NMR spectroscopy (Varian, Walnut Creek, CA, USA) and TEM (Jeol, Tokyo, Japan). Detailed methods for the characterization of block copolymer PEG- $b$-(PELG- $g$-(PZLL- $r$-PLL)) are supplied in the Supplementary material.

\section{Cytotoxicity assessment of PEG-b- (PELG-g-(PZLL-r-PLL))}

A MTT colorimetric assay was performed to assess the cytotoxic effects of PEG- $b$-(PELG- $g$-(PZLL- $r$-PLL)). ${ }^{33}$ Briefly, J82 cells were seeded at a density of $5 \times 10^{5} / \mathrm{L}$ cells per well in a 96-well poly-D-lysine-coated plate and maintained in Dulbecco's Modified Eagle's Medium supplemented with

Table I The stirring and dialyzing time and MWCO of the copolymers synthesis

\begin{tabular}{llll}
\hline Reaction mixture & $\begin{array}{l}\text { Stirring } \\
\text { (day) }\end{array}$ & $\begin{array}{l}\text { Dialyzing } \\
\text { (day) }\end{array}$ & $\begin{array}{l}\text { MWCO } \\
\text { (kDa) }\end{array}$ \\
\hline PEG-b-PBLG & 3 & 3 & 7 \\
PEG-b-PELG & 2 & 3 & 3.5 \\
PEG-b-(PELG-g-PZLL) & 3 & 3 & 7 \\
PEG-b-(PELG-g-(PZLL-r-PLL)) & 3 & 3 & 7
\end{tabular}

Abbreviations: MWCO, molecular weight cutoff; PEG-b-PBLG, poly(ethylene glycol)-b-poly( $\gamma$-benzyl L-glutamate); PEG-b-PELG, poly(ethylene glycol)-b-poly (ethylenediamine L-glutamate); PEG-b-(PELG-g-PZLL), poly(ethylene glycol)-b(poly(ethylenediamine L-glutamate)-g-poly( $($-benzyoxycarbonyl-I-lysine)); PEG-b(PELG-g-(PZLL-r-PLL)), poly(ethylene glycol)-b-(poly(ethylenediamine L-glutamate)g-poly(e-benzyoxycarbonyl-L-lysine)-r-poly(L-lysine)). 
$10 \%$ fetal bovine serum and $1 \%$ penicillin-streptomycin $(\mathrm{P} / \mathrm{S})$ at $37^{\circ} \mathrm{C}$ in a humidified incubator with $5 \% \mathrm{CO}_{2}$. The cells were treated with a concentration gradient of PEG- $b$ (PELG-g-(PZLL- $r$-PLL)) diluted with $0.9 \%$ normal saline, and then cultured at $37^{\circ} \mathrm{C}$ for $24 \mathrm{~h}$. The wells were subsequently added with MTT $(20 \mu \mathrm{L})$ and treated with ethanoldimethyl sulfoxide (DMSO) $(1: 1,100 \mu \mathrm{L})$ to solubilize the dark blue crystals of MTT formazan completely ( $\sim 20 \mathrm{~min})$. The absorbance or OD of per well at $570 \mathrm{~nm}$ was measured on a microplate multimode reader (Turner Biosystems, Madison, WI, USA). The blank control was taken from wells without cells, which were also cultured with the MTT. Cells incubated in the wells without polymers were used as a negative control. PEG- $b$-(PELG-g-(PZLL- $r$-PLL)) was used as potential cytotoxicity samples. The percentage of relative cell viability was calculated by comparing the values of treated cells with those of untreated cells, calculated as $\left(\mathrm{OD}_{\text {sample }}-\mathrm{OD}_{\text {blank }}\right) /\left(\mathrm{OD}_{\text {cells }}-\mathrm{OD}_{\text {blank }}\right) \times 100 \%$.

\section{Loading of LK, PTX, and LK/PTX in PEG-b-(PELG-g-(PZLL-r-PLL))}

To measure the encapsulation of LK by PEG- $b$-(PELG- $g$ (PZLL- $r$-PLL)), a fixed amount of LK $(5 \mathrm{mg} / \mathrm{mL})$ in PBS was associated with PEG- $b$-(PELG- $g$-(PZLL- $r$-PLL)) in PBS and then dialyzed in a dialysis bag (MWCO, $7 \mathrm{kDa})$. The PEG- $b$-(PELG- $g$-(PZLL- $r$-PLL))-loaded LK was verified by TEM and high-performance liquid chromatography (HPLC) (Supplementary material). The loading of PTX by PEG- $b$-(PELG- $g$-(PZLL- $r$-PLL)) was performed as method mentioned above. Concerning the co-loading of LK/PTX, the two drugs were first completely dissolved in PBS at a dose of $5 \mathrm{mg} / \mathrm{mL}$ each, and their co-loading to polymer was the same as that mentioned above.

\section{In vitro release of LK and PTX from PEG-b-(PELG-g-(PZLL-r-PLL))}

The release of LK or PTX from PEG- $b$-(PELG- $g$-(PZLL$r$-PLL)) was measured by dialysis (MWCO, $7 \mathrm{kDa})$ at $37^{\circ} \mathrm{C}$ with $5 \mathrm{~mL}$ of LK/PEG- $b$-(PELG- $g$-(PZLL- $r$-PLL)), PTX/PEG- $b$-(PELG- $g$-(PZLL- $r$-PLL)), and LK/PTX/PEG$b$-(PELG- $g$-(PZLL-r-PLL)) compound against $80 \mathrm{~mL}$ of 0.02 M PBS (pH 7.4), respectively. At 0.02-, 0.04-, 0.08-, 0.17-, 0.33-, 0.42-, 0.5-, 0.67-, 0.75-, 1-, 1.5-, 1.67-, 1.75-, 2-, 3-, 4-, and 5-day time interval, a fixed amount of release medium was extracted and replenished with a suitable amount of fresh release medium. The quantity of released LK or PTX remaining in the dialysis bag was measured by HPLC. The free LK and PTX in the absence of polymeric compound were also measured as a control.

\section{Inhibition ratio of cell proliferation}

J82 cells, in a logarithmic growth phase, were cultured in 96-well plates with $2.5 \times 10^{4}$ cells per well. At $24 \mathrm{~h}$ after cell incubation, $2.4 \mathrm{mg}$ (net drug content) LK, PTX, LK/polymer, PTX/polymer, or LK/PTX/polymer (dissolved in PBS) were added to each well. At $24 \mathrm{~h}$ after cell incubation, MTT solutions were added to each well and incubated for $4 \mathrm{~h}$. Then, the liquid supernatant was extracted and $200 \mu \mathrm{L}$ DMSO was added and shaken. Cells incubated in the wells without drugs were used as a control. The absorbance of the contents of each well was measured at $570 \mathrm{~nm}$ on a multimode reader. The inhibition ratio of cell proliferation was calculated by (drug group-Control group)/Control group $\times 100 \%$. The percentage of relative cell viability was calculated by comparing the values of drug-treated cells with those of nondrug-treated cells, calculated as $\left(\mathrm{OD}_{\text {control }}-\mathrm{OD}_{\text {drug }}\right) / \mathrm{OD}_{\text {control }} \times 100 \%$.

\section{Cell apoptosis}

J82 cells in logarithmic growth phase were cultured in 6-well plates with a density of $1 \times 10^{3}$ cells per well for $24 \mathrm{~h}$. Furthermore, $2.4 \mathrm{mg}$ (net drug content) LK, PTX, LK/polymer, PTX/ polymer, or LK/PTX/polymer were added to 6-well plates. The cells without drugs were selected as a control. At $48 \mathrm{~h}$ after cell coincubation, liquid supernatants were eliminated. Then, $1 \mathrm{~mL}$ of bisbenzimide Hoechst 33342 trihydrochloride fluorochrome (Sigma) was added and co-incubated at $37^{\circ} \mathrm{C}$ for $15 \mathrm{~min}$. The unconjugated Hoechst 33242 fluorochrome was then washed away by PBS. Subsequently, the image was observed through inverted microscope. The cell apoptosis rate was calculated by comparing the numbers $(N)$ of apoptotic cells with those of total cells, calculated as $N_{\text {apoptotic cells }} / N_{\text {total cells }} \times 100 \%$.

\section{Blood concentration of LK and PTX}

Sprague Dawley male rats (160-220 g) were administered a dose of $20 \mathrm{mg} / \mathrm{kg}$ bw LK or LK/PEG- $b$-(PELG- $g$-(PZLL- $r$ PLL)) by abdominal subcutaneous injection. At 0.02-, 0.04-, 0.08-, 0.17-, 0.25-, 0.33-, 0.42-, 0.5-, 0.67-, 0.75-, 1-, 1.5-, 1.67-, 1.75-, 2-, 3-, 4-, and 5-day time interval, $0.2 \mathrm{~mL}$ of blood was extracted and separated immediately by centrifugation at $3,000 \mathrm{rpm}$ at $4{ }^{\circ} \mathrm{C}$ for $20 \mathrm{~min}$. The concentration of LK or LK/PEG- $b$-(PELG- $g$-(PZLL- $r$-PLL)) in rat blood was measured by HPLC. The blood concentration of PTX or PTX/PEG- $b$-(PELG- $g$-(PZLL- $r$-PLL)) was measured by the same method mentioned above.

\section{Bladder cancer animal procedure}

To refer to previous studies, ${ }^{34,35}$ Sprague Dawley male rats (160-220 g) were perfused with $\mathrm{MNU}(0.2 \mathrm{~mL}, 10 \mathrm{mg} / \mathrm{mL})$ 
in the urinary bladder. Rats were administered MNU once at 1-week intervals, and the total number of administrations was six. Animals were housed in light- and temperaturecontrolled rooms and were given food and water ad libitum during the course of the modeling. Finally, after the animal model has been made, the 24-h urine was collected from rats with metabolic cage and centrifugated at 2,000 rpm for 15 min to obtain the sediment. The smear of the sediment was examined with H\&E stain and acridine orange/ethidium bromide stain under the optical microscope and laser confocal microscope, respectively. Microscopically, tumor cells were found to indicate the success of the modeling.

Sixty bladder cancer rats were equally randomized into six groups: 1) PEG- $b$-(PELG- $g$-(PZLL- $r$-PLL)) group (Control group), wherein PEG- $b$-(PELG-g-(PZLL-r-PLL)) (444.26 mg/kg bw, based on loading capacity of copolymer, dissolved in PBS) was administered by a single-dose injection into the subcutaneous tissue of abdomen o.d.; 2) LK group, wherein LK (20 mg/kg bw, dissolved in PBS) was administered by a single-dose injection into the subcutaneous tissue of abdomen o.d.; 3) PTX group, wherein PTX (20 mg/kg bw, dissolved in PBS) was administered by a single-dose injection into the subcutaneous tissue of abdomen o.d.; 4) LK/PEG- $b$-(PELG-g-(PZLL- $r$-PLL)) group (LK/P group), wherein LK/PEG- $b$-(PELG- $g$-(PZLL- $r$-PLL)) $(296.74$ mg/kg bw [containing $20 \mathrm{mg} / \mathrm{kg} \mathrm{LK}$, based on loading capacity of copolymer], dissolved in PBS) was administered by a singledose injection into the subcutaneous tissue of abdomen once every 5 days; 5) PTX/PEG- $b$-(PELG- $g$-(PZLL-r-PLL)) group (PTX/P group), wherein PTX/PEG- $b$-(PELG- $g$-(PZLL- $r$ PLL)) (484.26 mg/kg bw [containing $20 \mathrm{mg} / \mathrm{kg}$ PTX, based on loading capacity of copolymer], dissolved in PBS) was administered by a single-dose injection into the subcutaneous tissue of abdomen once every 5 days; and 6) LK/PTX/ PEG- $b$-(PELG- $g$-(PZLL-r-PLL)) group (LK/PTX/P group), wherein LK/PTX/PEG- $b$-(PELG-g-(PZLL-r-PLL)) (484.26 $\mathrm{mg} / \mathrm{kg}$ bw [containing $20 \mathrm{mg} / \mathrm{kg} \mathrm{LK}$ and $20 \mathrm{mg} / \mathrm{kg}$ PTX, based on loading capacity of copolymer], dissolved in PBS) was administered by a single-dose injection into the subcutaneous tissue of abdomen once every 5 days.

\section{Tumor inhibition evaluation in bladder cancer rats}

Rats in the different groups mentioned above were sacrificed by decapitation at a given time (day 22 after the completion of the modeling). The five bladder tumor tissues per group were removed to weigh the wet tissue and then placed in a vacuum-drying oven at $80^{\circ} \mathrm{C}$ until constant weight (the dry weight, $W$, in grams; $\sim 36 \mathrm{~h})$. Another five bladder tumor tissues in each group were used for histopathological examination, immunohistochemical assay, and Western blotting analysis referring to previous study. ${ }^{36}$

\section{Survival evaluation in bladder cancer rats}

Another sixty bladder cancer rats were equally randomized into six groups based on the method mentioned above, and rats grew naturally until death. The lifespan was recorded, and the life prolongation rate was calculated by comparing the survival time (days, $D$ ) of drug-treated rats with that of nondrugtreated rats, calculated as $\left(D_{\text {treat }}-D_{\text {control }}\right) / D_{\text {control }} \times 100 \%$.

\section{Histopathological observation}

The bladder cancer tissue was fixed in 4\% neutral PBS/ paraformaldehyde, paraffin-embedded, sliced into $4-\mu \mathrm{m}$ sections, and stained with H\&E staining. The histopathological changes were examined under the optical microscope (Leica, Nussloch, Germany). The bladder cancer incidence in rats is estimated by histopathological examination based on the classification of tumor of the urinary system from World Health Organization. ${ }^{37}$ The Class I comprises non-invasive papillary urothelial neoplasm of low malignant potential and low-grade non-invasive papillary urothelial carcinoma, and Class II is high-grade non-invasive papillary urothelial carcinoma.

\section{Immunohistochemical assay}

The intratumoral MVD in the bladder cancer tissue were measured by immunohistochemistry. ${ }^{38,39}$ The $4-\mu \mathrm{m}$ rat bladder tissue paraffin sections were deparaffinized, rehydrated, and treated with $3 \%$ hydrogen peroxide $\left(\mathrm{H}_{2} \mathrm{O}_{2}\right)$ to remove endogenous peroxidase. Then they were incubated with the primary anti-CD34 antibody (Abcam, Shanghai, China) overnight at $4^{\circ} \mathrm{C}$. The secondary antibody was horseradish peroxidase-labeled streptavidin. Microphotographs were taken with Leica DM2000LED (Leica) imaging system. The average number of CD34-positive microvessels in five sections at $400 \times$ magnification was counted by pathologists.

\section{Western blotting analysis}

The Western blotting analysis was performed following the previous reports. ${ }^{40-42}$ Briefly, the rat bladder tumor tissue was homogenized in protein lysate buffer and an equal amount of homogenate was subjected to $10 \%$ sodium dodecyl sulfatepolyacrylamide gels and then electrophoretically transferred to the nitrocellulose membrane. After blocking with 5\% skim milk in Tris-buffered saline with Tween-20 for $1 \mathrm{~h}$, the membrane 
was immunoblotted with primary antibodies (anti-p53 and cyclin $\mathrm{B} 1$ antibodies) overnight at $4^{\circ} \mathrm{C}$ and treated with alkaline phosphatase-conjugated secondary antibodies. Blots were stained with $\beta$-actin antibody. The products were visualized and analyzed with enhanced chemiluminescence and FluorChem system (Thermo Fisher Scientific, Waltham, MA, USA).

\section{Compliance with ethical standards}

Sprague Dawley male rats (160-220 g) were housed at Jiaxing University Medical College (Jiaxing, China). The procedures and care of Sprague Dawley male rats were authorized by the institutional ethics committee of Jiaxing University Medical College (JUMC-2017012). The experiments conformed to the guide for the care and use of laboratory animals published by US National Institutes of Health (NIH Publication updated in 2011).

\section{Statistical analysis}

Data are expressed as the mean \pm SD. Microsoft Excel 2016 database (Microsoft, Redmond, WA, USA) and SPSS 19.0 software (IBM Corp., Armonk, NY, USA) were used to record and analyze all the data. Statistical differences were determined using Student's $t$-test or one-way analysis of variance with post hoc test. A value of $<0.05(p<0.05)$ in a two-tailed test was considered statistically significant.

\section{Results}

\section{Synthesis and characterization of PEG- $b$ - (PELG-g-(PZLL-r-PLL))}

The synthesis route and structure of PEG- $b$-(PELG- $g$-(PZLL$r$-PLL)) is demonstrated in Figure 1. The PEG- $b$-(PELG- $g$ (PZLL- $r$-PLL)) nanoparticle contained a linear-like PEG block and a brush-like PZLL-r-PLL block. The molecular weight of PEG- $b$-(PELG-g-(PZLL-r-PLL)) was $34.5 \mathrm{kDa}$ based on ${ }^{1} \mathrm{H}$ NMR (Figure 2A). The images of PEG- $b$ (PELG- $g$-(PZLL- $r$-PLL)), LK/PEG- $b$-(PELG- $g$-(PZLL$r$-PLL)), PTX/PEG- $b$-(PELG- $g$-(PZLL- $r$-PLL)), and LK/ PTX/PEG- $b$-(PELG-g-(PZLL-r-PLL)) were observed by TEM and they displayed an orbicular structure and the average diameters were $41,83,78$, and $89 \mathrm{~nm}$, respectively (Figure 2B; Table 2).

\section{Loading capacity of LK, PTX, and LK/PTX in PEG-b-(PELG-g-(PZLL-r-PLL))}

LK and PTX were efficiently loaded by the copolymer PEG$b$-(PELG-g-(PZLL-r-PLL)) at a physiological $\mathrm{pH}$ through electrostatic interaction and hydrophobic interaction, respectively, to put LK or PTX in the copolymer (mass ratio, 1:5) and dialyzed against PBS (Figure 2C). The loading of LK in PEG$b$-(PELG- $g$-(PZLL- $r$-PLL)) was determined to be $\sim 6.74 \%$ by HPLC. Likewise, the loading of PTX was $\sim 4.13 \%$ and the co-loading of LK/PTX was $\sim 10.34 \%$ (Table 2).

\section{In vitro release of LK and PTX from PEG-b-(PELG-g-(PZLL-r-PLL))}

The LK release in vitro was detected by dialysis. Under 0.02 M PBS (physiological condition), sustained release of LK was observed, with $\sim 11.17 \%$ of LK released over a period of 4 h, $\sim 59.66 \%$ over a period of 3 days, and $\sim 67.89 \%$ over a period of 5 days. Likewise, a sustained release of PTX was observed, with $\sim 11.28 \%$ of PTX released over a period of $8 \mathrm{~h}, \sim 51.24 \%$ over a period of 3 days, and $\sim 55.68 \%$ over a period of 5 days (Figure 2D).

\section{Relative cell viability}

The cytotoxicity of PEG- $b$-(PELG- $g$-(PZLL- $r$-PLL)) on J82 cells was monitored within 24-h culturing. PEG- $b$-(PELG$g$-(PZLL-r-PLL)) was noncytotoxic at the concentrations of $\leq 50 \mu \mathrm{g} / \mathrm{mL}$, and it exhibited a low cytotoxicity and high relative cell viability (minimum mean was $\sim 81.8 \%$ ), even when administered at a maximum dose of $300 \mu \mathrm{g} / \mathrm{mL}$ (Figure 2E).

\section{Inhibition ratio of cell proliferation}

As shown in Figure 2F, the absorbance values were lower in the LK and PTX groups than those in the Control group $(p<0.01)$, whereas they were lower in the LK/P and PTX/P groups than those in the LK and PTX groups $(p<0.05)$. The absorbance value was substantially lower in the LK/PTX/P group than that in the LK/P and PTX/P groups $(p<0.01)$. Correspondingly, the inhibition rates of $\mathrm{J} 82$ cell proliferation were higher in the LK and PTX groups than those in the Control group $(p<0.01)$. They were higher in the LK/P and PTX/P groups than those in the LK and PTX groups $(p<0.05)$. The inhibition rate of cell proliferation was substantially higher in the LK/PTX/P group than that in the LK/P and PTX/P groups $(p<0.01$; Figure $2 \mathrm{G}$ ). These results suggest that the copolymer LK/PTX/PEG- $b$-(PELG- $g$-(PZLL- $r$-PLL)) could inhibit the proliferation of $\mathrm{J} 82$ cells more effectively.

\section{Cell apoptosis}

Cell apoptosis level was higher in the LK, PTX, LK/P, and PTX/P groups compared with that in the Control group $(p<0.01)$. Furthermore, it was remarkably higher in the LK/ PTX/P group compared with that in the LK/P and PTX/P groups $(p<0.01$; Figure 3$)$. These data indicate that the 
<smiles>[X]C(CN)OCCOC</smiles>

PEG-NH

PEG-b-PBLG

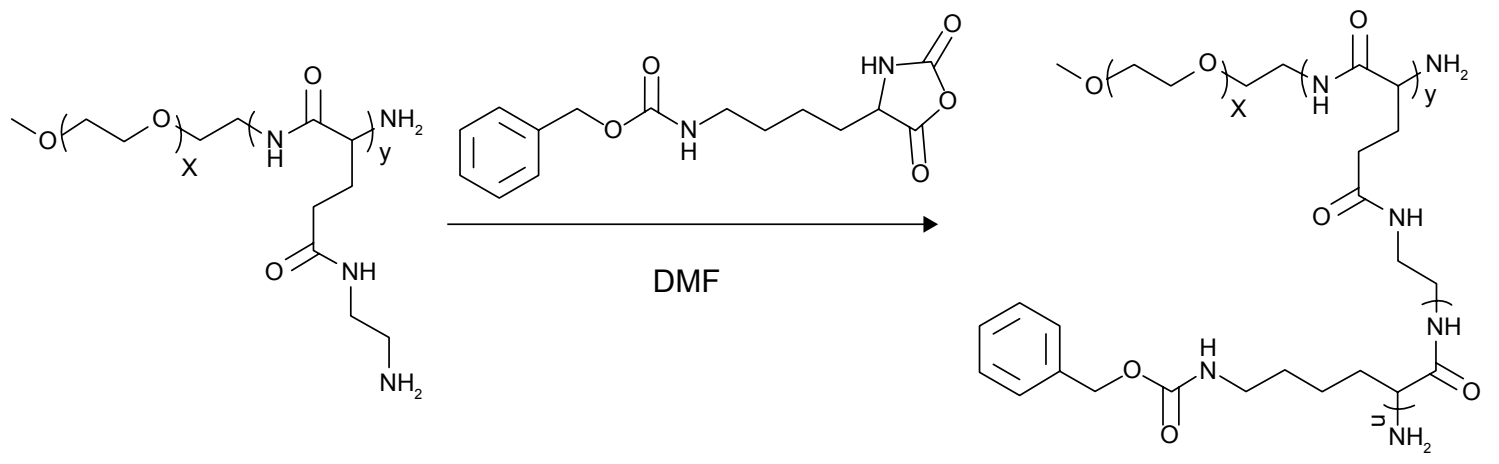

PEG-b-PELG

PEG-b-(PELG-g-PZLL)

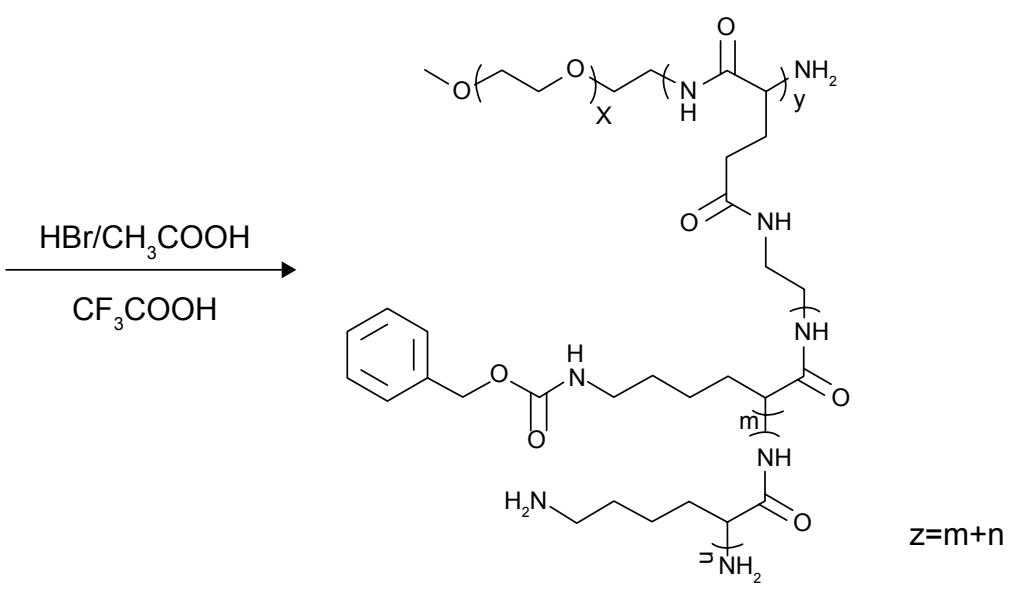

PEG-b-(PELG-g-(PZLL-r-PLL))

Figure I Synthesis of PEG-b-(PELG-g-(PZLL-r-PLL)).

Note: $x, y, m$, and $n$ represent the degree of polymerization.

Abbreviations: 2-HP, 2-hydroxypyridine; DMF, N,N-dimethylformamide; PEG- $\mathrm{NH}_{2}$, poly(ethylene glycol) amine; PEG-b-PBLG, poly(ethylene glycol)-b-poly( $\gamma$-benzyl L-glutamate); PEG-b-PELG, poly(ethylene glycol)-b-poly(ethylenediamine L-glutamate); PEG-b-(PELG-g-PZLL), poly(ethylene glycol)-b-(poly(ethylenediamine L-glutamate)-g-poly

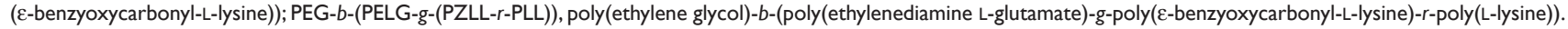

copolymer LK/PTX/PEG- $b$-(PELG- $g$-(PZLL-r-PLL)) could result in $\mathrm{J} 82$ cell apoptosis more remarkably.

\section{Blood concentration}

A pharmacodynamic study showed that in rats treated with an LK solution, the blood LK concentrations increased rapidly and reached a peak within $2 \mathrm{~h}(0.52$ $\mu \mathrm{g} / \mathrm{mL})$, followed by a significant decline after $6 \mathrm{~h}(0$ $\mu \mathrm{g} / \mathrm{mL})$. By contrast, the concentration of the LK/PEG$b$-(PELG-g-(PZLL- $r$-PLL)) complex gradually peaked within $6 \mathrm{~h}(0.34 \mu \mathrm{g} / \mathrm{mL})$ and remained at a comparatively low level for 5 days $(0.03 \mu \mathrm{g} / \mathrm{mL}$ on day 5 ; Figure $4 \mathrm{~A})$. 
A

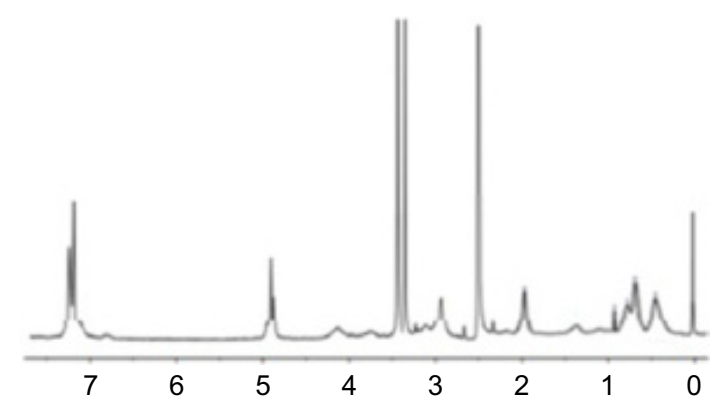

B
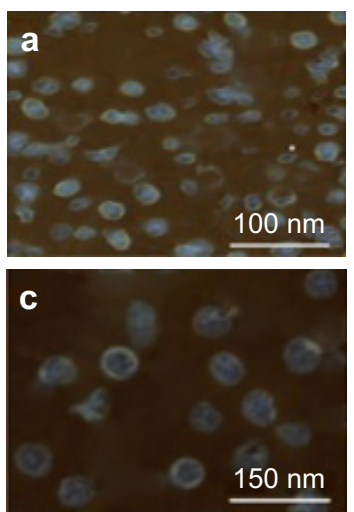

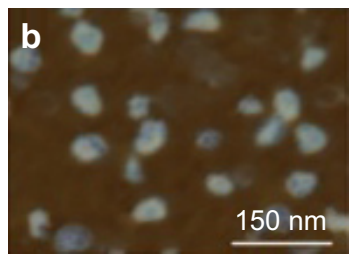

d

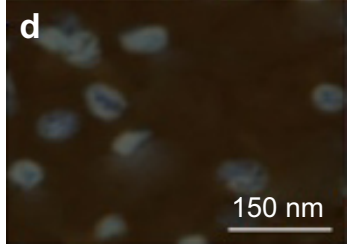

C

D

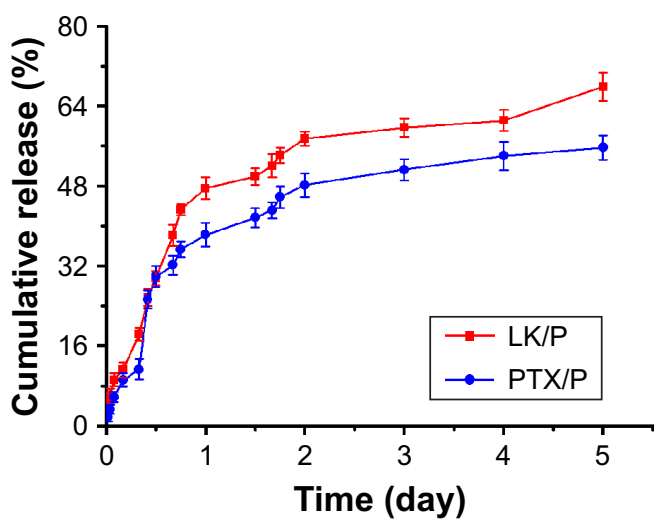

$\mathbf{F}$

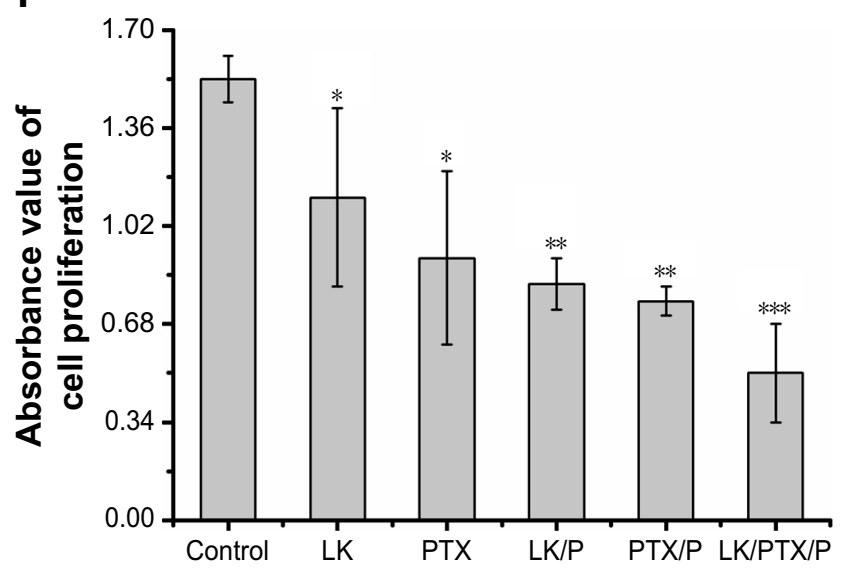

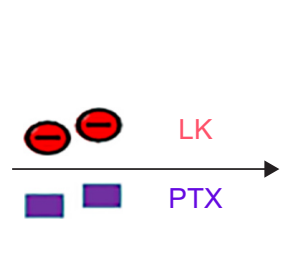

E
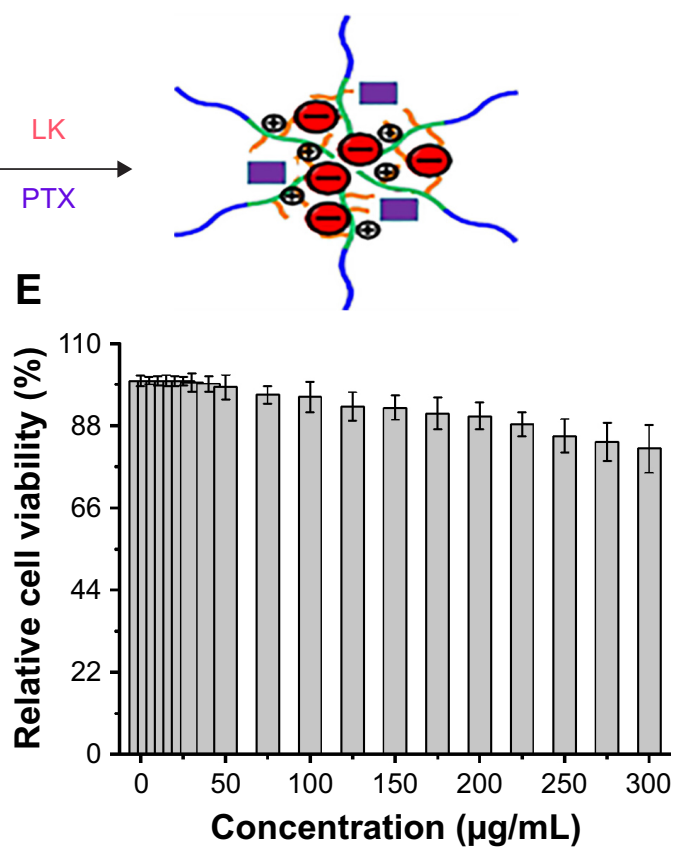

G

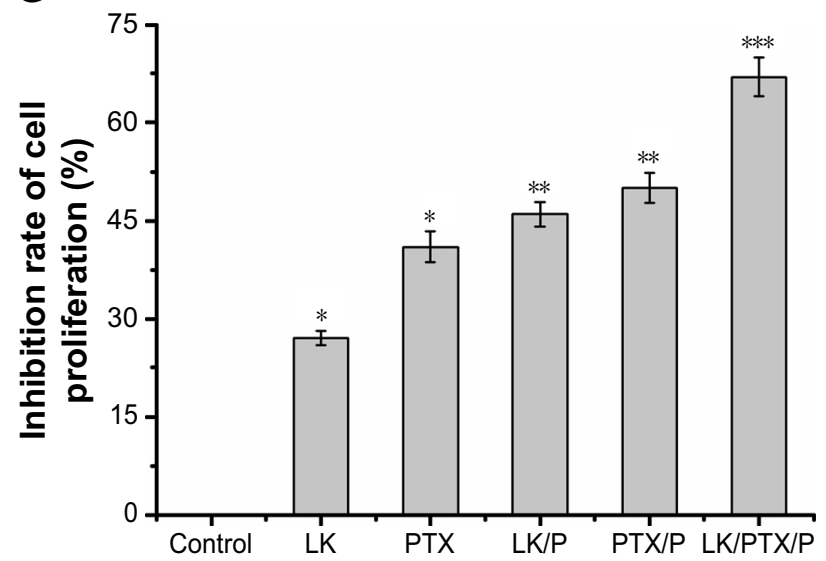

Figure 2 Characterization of nanocomplexes.

Notes: (A) 'H NMR spectra of PEG-b-(PELG-g-(PZLL-r-PLL)); (B) TEM image of copolymers, (a) PEG-b-(PELG-g-(PZLL-r-PLL)), (b) LK/PEG-b-(PELG-g-(PZLL-r-PLL)), (c) PTX/PEG-b-(PELG-g-(PZLL-r-PLL)), and (d) LK/PTX/PEG-b-(PELG-g-(PZLL-r-PLL)); (C) Loading pattern diagram of PEG-b-(PELG-g-(PZLL-r-PLL)); (D) Cumulative releasing profile of LK and PTX from PEG-b-(PELG-g-(PZLL-r-PLL)) complexes $(n=5)$; (E) Relative cell viability ( $n=5)$; $(\mathbf{F})$ Absorbance value of cell proliferation ( $n=5)$; $(\mathbf{G})$ Inhibition ratio of cell proliferation $(n=5)$. Data are expressed as the mean \pm SD. ${ }^{*} p<0.01$ vs control, $* * p<0.05$ vs LK or PTX, *** $p<0.0$ I vs LK/P or PTX/P.

Abbreviations: 'H NMR, 'H nuclear magnetic resonance; LK, lumbrokinase; P, PEG-b-(PELG-g-(PZLL-r-PLL)); PEG-b-(PELG-g-(PZLL-r-PLL)), poly(ethylene glycol)-b(poly(ethylenediamine L-glutamate)-g-poly(E-benzyoxycarbonyl-L-lysine)-r-poly(L-lysine)); PTX, paclitaxel. 
Table 2 MW, TEM, LK-, and PTX-loading capacity of the nanocarrier

\begin{tabular}{llll}
\hline Sample & $\boldsymbol{M}_{\mathbf{n}}(\mathbf{k D a}) /{ }^{\prime} \mathbf{H}$ NMR & TEM $(\mathbf{n m})$ & Loading capacity (\%) \\
\hline P & 34.5 & $4 I \pm 2$ & NA \\
LK/P & NA & $83 \pm 3$ & 6.74 \\
PTX/P & NA & $78 \pm 2$ & 4.13 \\
LK/PTX/P & NA & $89 \pm 3$ & $10.34^{\mathrm{a}}$
\end{tabular}

Notes: ${ }^{a}$ The negatively charged LK combines with a positively charged PLL via electrostatic interactions and hydrophobic PTX combines with PZLL through hydrophobic interaction at $\mathrm{pH} 7.4$, respectively.

Abbreviations: 'H NMR, 'H nuclear magnetic resonance; LK, lumbrokinase; MW, molecular weight; NA, not applicable; P, PEG-b-(PELG-g-(PZLL-r-PLL)); PLL, poly(Llysine); PZLL, poly( $\varepsilon$-benzyoxycarbonyl-L-lysine); PTX, paclitaxel; TEM, transmission electron microscopy.
Similarly, the blood PTX concentrations increased rapidly and reached a peak within $1 \mathrm{~h}(16.7 \mu \mathrm{g} / \mathrm{mL})$, followed by a significant decline after $12 \mathrm{~h}(0 \mu \mathrm{g} / \mathrm{mL})$. The concentration of the PTX/PEG- $b$-(PELG- $g$-(PZLL- $r$-PLL)) complex gradually peaked within $4 \mathrm{~h}(9.9 \mu \mathrm{g} / \mathrm{mL})$ and remained at comparatively low levels for 5 days $(0.13 \mu \mathrm{g} /$ $\mathrm{mL}$ on day 5; Figure 4B). These results clearly indicate that the nanocarrier PEG- $b$-(PELG- $g$-(PZLL- $r$-PLL)) may effectively enhance the release time of two drugs in vivo.
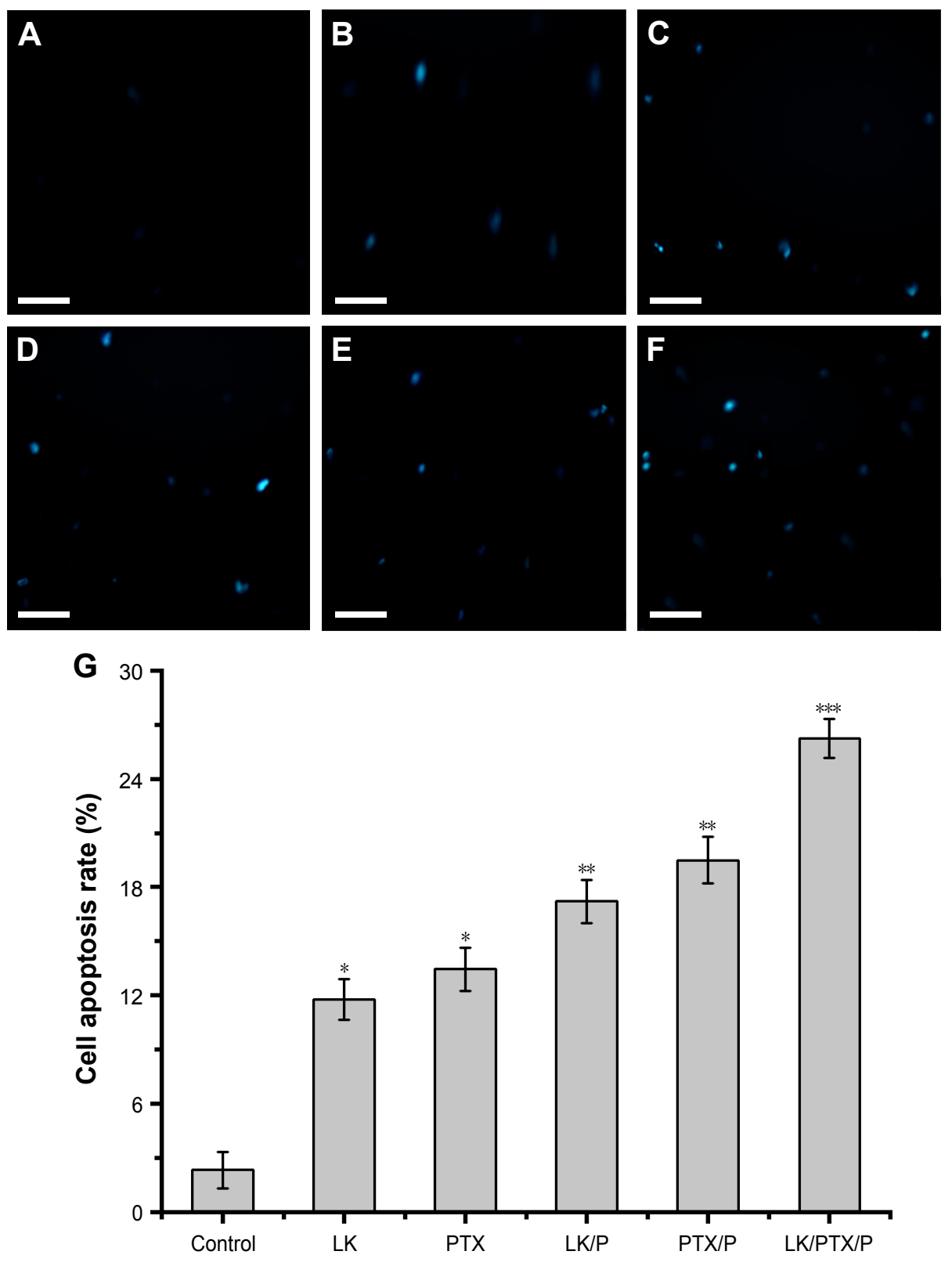

Figure 3 Cell apoptosis.

Notes: (A) Control; (B) LK; (C) PTX; (D) LK/P; (E) PTX/P; (F) LK/PTX/P; (G) Cell apoptosis rate. Scale bar $40 \mu \mathrm{m}$. Data are expressed as the mean \pm SD, $\mathrm{n}=5$. *p $<0.0$ I vs Control, ${ }^{* *} p<0.05$ vs LK or PTX, ${ }^{* * *} p<0.0$ I vs LK/P or PTX/P.

Abbreviations: LK, lumbrokinase; P, PEG-b-(PELG-g-(PZLL-r-PLL)); PEG-b-(PELG-g-(PZLL-r-PLL)), poly(ethylene glycol)-b-(poly(ethylenediamine L-glutamate)-g-poly(عbenzyoxycarbonyl-L-lysine)-r-poly(L-lysine)); PTX, paclitaxel. 

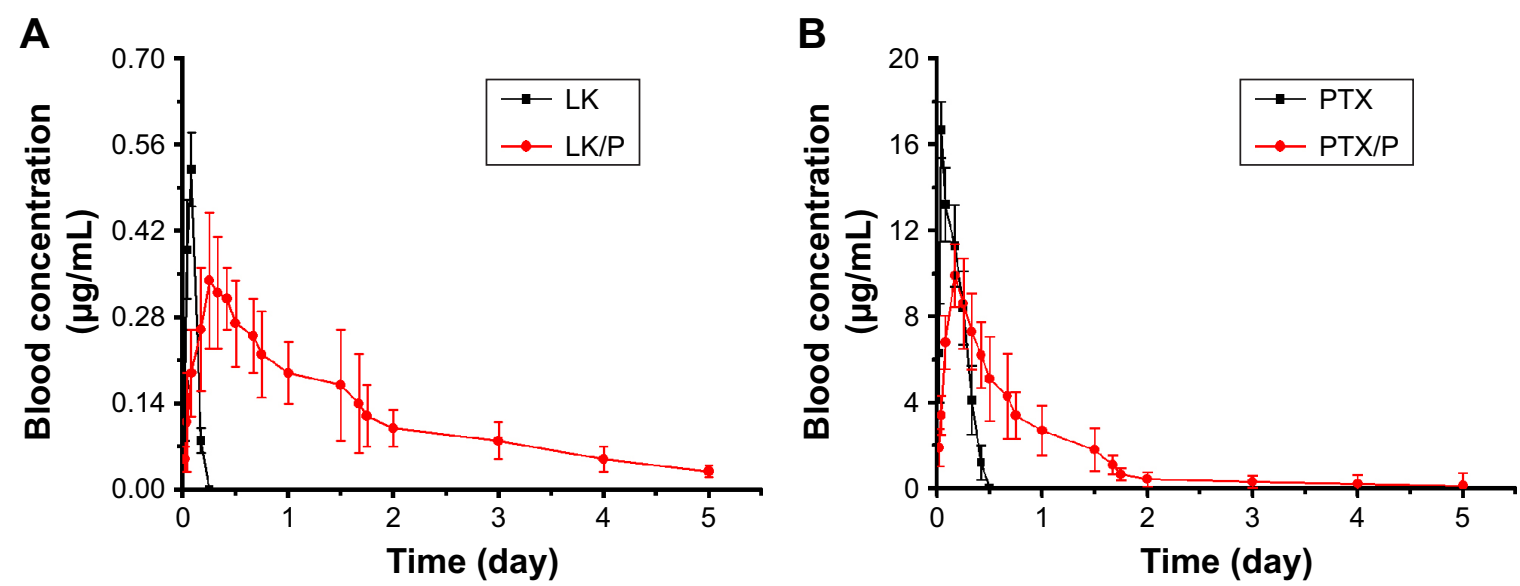

Figure 4 Blood concentration of LK and PTX

Notes: (A) Blood LK concentration; (B) Blood PTX concentration. Data are expressed as the mean \pm SD, $n=7$.

Abbreviations: LK, lumbrokinase; P, PEG-b-(PELG-g-(PZLL-r-PLL)); PEG-b-(PELG-g-(PZLL-r-PLL)), poly(ethylene glycol)-b-(poly(ethylenediamine L-glutamate)-g-poly( $\varepsilon-$ benzyoxycarbonyl-L-lysine)-r-poly(L-lysine)); PTX, paclitaxel.

\section{Lifespan and life prolongation rate of rats}

The rat lifespan was longer in the LK, PTX, LK/P, and PTX/P groups than that in the Control group $(p<0.01)$. It was remarkably longer in the LK/PTX/P group than that in the LK/P and PTX/P groups $(p<0.01$; Figure $5 \mathrm{~A})$. Correspondingly, the life prolongation rate was higher in the LK, PTX, LK/P, and PTX/P groups than that in the Control group $(p<0.01)$. The life prolongation rate was remarkably higher in the LK/PTX/P group than that in the LK/P and PTX/P groups $(p<0.01$; Figure 5B). These results suggest that the application of the copolymer LK/PTX/PEG- $b$-(PELG- $g$-(PZLL- $r$-PLL)) significantly prolongs the lifespan of bladder cancer rats.

\section{Average tumor weight and tumor inhibition rate of rats}

The average tumor weight was lower in the LK, PTX, LK/P, and PTX/P groups than that in the Control group $(p<0.01)$.
It was markedly lower in the LK/PTX/P group than that in the LK/P and PTX/P groups ( $p<0.01$; Figure $6 \mathrm{~A}$ ). Correspondingly, the tumor inhibition rate was higher in the LK, PTX, LK/P, and PTX/P groups than that in the Control group $(p<0.01)$, while it was markedly higher in the LK/PTX/P group than that in the LK/P and PTX/P groups $(p<0.01$; Figure 6B). These results indicate that the copolymer LK/PTX/PEG- $b$-(PELG-g-(PZLL- $r$-PLL)) significantly inhibits the growth of the tumor in the bladder cancer rats.

\section{Histopathological estimation and bladder cancer incidence in rats}

Disorganized cells, pathological mitotic figure, and papillary hyperplasia in local or multiple regions were observed in the Control group. Cell abnormalities in the LK, PTX, LK/P, and PTX/P groups were less severe than those in the Control group. Cell abnormalities in the LK/PTX/P group
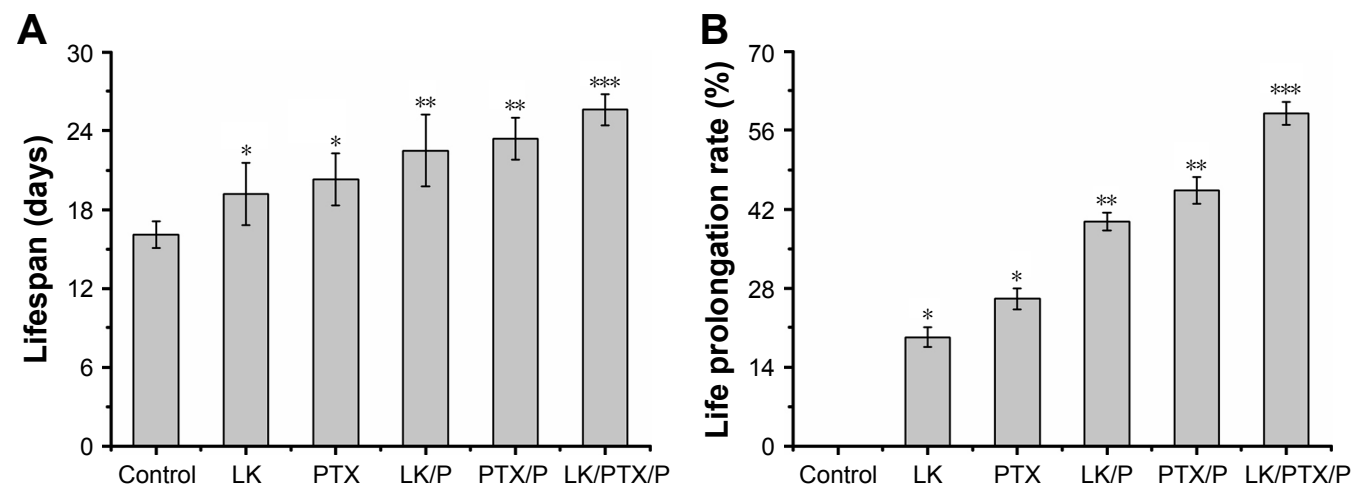

Figure $\mathbf{5}$ Lifespan and life prolongation rate.

Notes: (A) Lifespan; (B) Life prolongation rate. Data are expressed as the mean \pm SD, $n=10$. $* p<0.0$ I vs Control, **p $<0.05$ vs LK or PTX, *** $p<0.0$ I vs LK/P or PTX/P. Abbreviations: LK, lumbrokinase; P, PEG-b-(PELG-g-(PZLL-r-PLL)); PEG-b-(PELG-g-(PZLL-r-PLL)), poly(ethylene glycol)-b-(poly(ethylenediamine L-glutamate)-g-poly( $\varepsilon-$ benzyoxycarbonyl-L-lysine)-r-poly(L-lysine)); PTX, paclitaxel. 
A

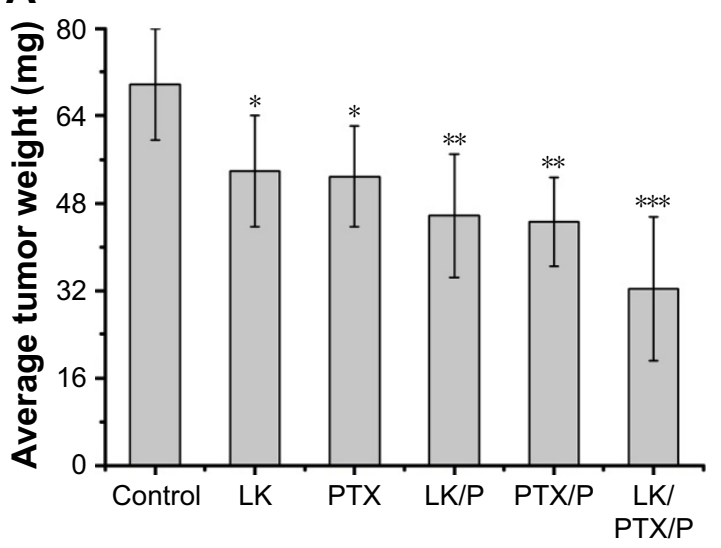

B

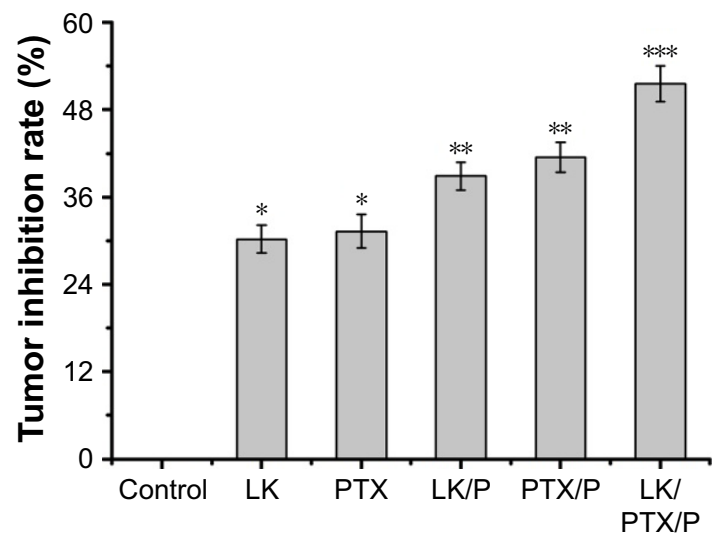

Figure 6 Average tumor weight and tumor inhibition rate.

Notes: (A) Average tumor weight; (B) Tumor inhibition rate. Data are expressed as the mean \pm SD, $n=10$. $* p<0.0$ I vs Control, $* * p<0.05$ vs $L K$ or PTX, $* * * p<0.01$ vs LK/P or PTX/P.

Abbreviations: LK, lumbrokinase; P, PEG-b-(PELG-g-(PZLL-r-PLL)); PEG-b-(PELG-g-(PZLL-r-PLL)), poly(ethylene glycol)-b-(poly(ethylenediamine L-glutamate)-g-poly(Ebenzyoxycarbonyl-L-lysine)-r-poly(L-lysine)); PTX, paclitaxel.

were significantly less severe than those of the LK/P and PTX/P groups (Figure 7). The bladder cancer incidence in rats was shown in Table 3. These results demonstrate that the treatment with the copolymer LK/PTX/PEG- $b$-(PELG$g$-(PZLL- $r$-PLL)) significantly inhibits the occurrence and development of tumors in the bladder cancer rats.

\section{MVD in the bladder cancer tissue of rats}

The MVD was lower in the LK, PTX, LK/P, and PTX/P groups than that in the Control group $(p<0.01)$. MVD was substantially lower in the LK/PTX/P group than that in the LK/P and PTX/P groups ( $p<0.01$; Figure 8$)$. These data suggest that the copolymer LK/PTX/PEG- $b$-(PELG- $g$-(PZLL$r$-PLL)) significantly inhibits the tumor angiogenesis, thus inhibiting tumor progression.

\section{Expression of $\mathrm{p} 53$ and cyclin $\mathrm{BI}$ in the bladder cancer tissue of rats}

The expression of $\mathrm{p} 53$ was higher in the LK, PTX, LK/P, and PTX/P groups than that in the Control group $(p<0.01)$, while
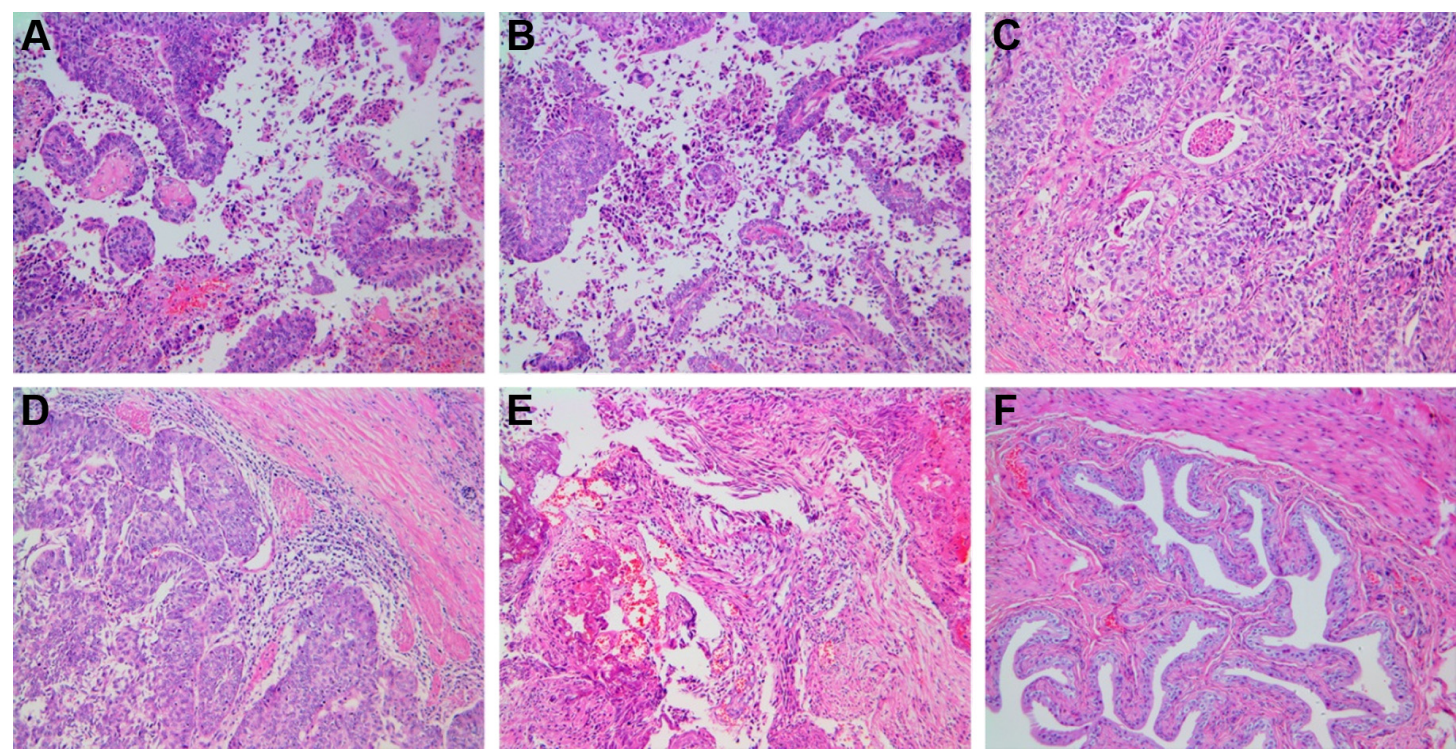

Figure 7 Histopathology.

Notes: (A) Control; (B) LK; (C) PTX; (D) LK/P; (E) PTX/P; (F) LK/PTX/P. Disorganized cells, pathological mitotic figure, and papillary hyperplasia are observed in local or multiple regions in the Control group; the cell abnormality in LK and PTX groups is lower than that of the Control group; the cell abnormality in the LK/P and PTX/P groups is lower than that of the LK and PTX groups; and the cell abnormality in the LK/PTX/P group is significantly lower than that of the LK/P and PTX/P groups. HematoxylinEosin staining, magnification $\times 100$.

Abbreviations: LK, lumbrokinase; P, PEG-b-(PELG-g-(PZLL-r-PLL)); PEG-b-(PELG-g-(PZLL-r-PLL)), poly(ethylene glycol)-b-(poly(ethylenediamine L-glutamate)-g-poly(عbenzyoxycarbonyl-L-lysine)-r-poly(L-lysine)); PTX, paclitaxel. 
Table 3 The bladder cancer incidence in rats

\begin{tabular}{|c|c|c|c|}
\hline \multirow[t]{2}{*}{ Group } & \multicolumn{2}{|c|}{ Transitional-cell carcinoma } & \multirow{2}{*}{$\begin{array}{l}\text { Canceration } \\
\text { rate }(\%)\end{array}$} \\
\hline & Class I and $<$ Class I & $>$ Class I & \\
\hline Control & $11 / 20$ & $6 / 20$ & 85.0 \\
\hline LK & $6 / 20$ & $5 / 20$ & 55.0 \\
\hline PTX & $5 / 20$ & $5 / 20$ & 50.0 \\
\hline LK/P & $4 / 20$ & $3 / 20$ & 35.0 \\
\hline PTX/P & $4 / 20$ & $2 / 20$ & 30.0 \\
\hline LK/PTX/P & $3 / 20$ & $2 / 20$ & 25.0 \\
\hline
\end{tabular}

Abbreviations: LK, lumbrokinase; P, PEG-b-(PELG-g-(PZLL-r-PLL)); PTX, paclitaxel.

p53 expression was substantially higher in the LK/PTX/P group than that in the LK/P and PTX/P groups $(p<0.01)$. The expression of cyclin B1 was lower in the LK, PTX, LK/P, and $\mathrm{PTX} / \mathrm{P}$ groups than that in the Control group $(p<0.01)$. It was substantially lower in the LK/PTX/P group than that in the LK/P and PTX/P groups ( $p<0.01$; Figure 9). These results strongly suggest that the copolymer LK/PTX/PEG- $b$-(PELG$g$-(PZLL- $r$-PLL)) significantly inhibits the tumor cell mitosis, thus inhibiting the uncontrolled cancer cell growth.

\section{Discussion}

Bladder cancer is a common cancer in urinary surgical practice. Multiple therapies have been performed in clinics. Nevertheless, the recurrence rate increases yearly, even when surgical intervention is utilized. To date, drug therapy has shown inauspicious efficacy with higher adverse effects. ${ }^{43,44}$ LK is a traditional Chinese medicine that can reduce the coagulation of platelets and augment the dissolution of thrombi in the blood.22 LK plays an important role in thrombosis-related diseases. ${ }^{22}$ Recently, LK was found to have an anti-tumor effect. ${ }^{45,46}$ LK not only inhibited tumor growth but also possessed significant anti-tumor activity. ${ }^{22,45}$ However, the
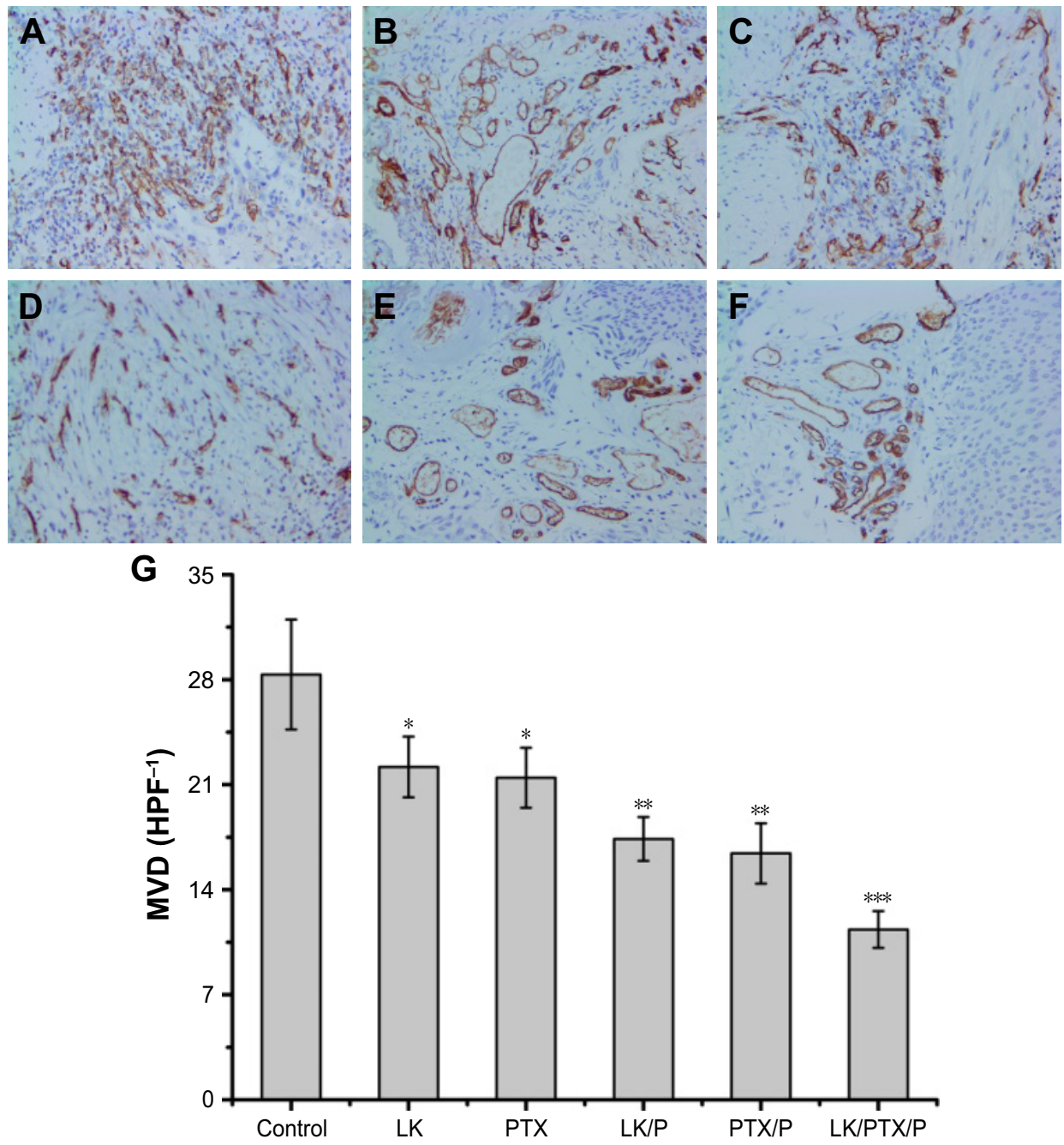

Figure 8 CD34 expression and MVD in the rat bladder cancer tissue.

Notes: (A) Control; (B) LK; (C) PTX; (D) LK/P; (E) PTX/P; (F) LK/PTX/P; (G) MVD. Immunohistochemical staining, magnification $\times 200$. Data are expressed as the mean $\pm \mathrm{SD}, \mathrm{n}=10$. ${ }^{*} p<0.01$ vs Control, ${ }^{* *} p<0.05$ vs LK or PTX, $* * * p<0.01$ vs LK/P or PTX/P.

Abbreviations: HPF, high-power field in an optical microscope; LK, lumbrokinase; MVD, microvessel density; P, PEG-b-(PELG-g-(PZLL-r-PLL)); PEG-b-(PELG-g-(PZLL-rPLL)), poly(ethylene glycol)-b-(poly(ethylenediamine L-glutamate)-g-poly(E-benzyoxycarbonyl-L-lysine)-r-poly(l-Lysine)); PTX, paclitaxel. 


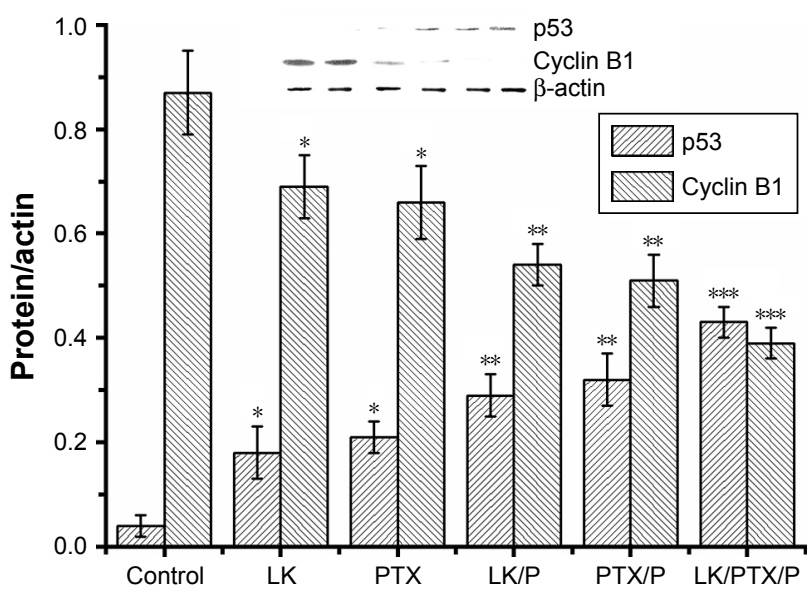

Figure 9 Expression of $\mathrm{p} 53$ and cyclin $\mathrm{BI}$ in the rat bladder cancer tissue. Notes: Data are expressed as the mean \pm SD, $n=10$. ${ }^{*} p<0.0$ I vs Control, ${ }^{* *} p<0.05$ vs LK or PTX, *** $p<0.01$ vs LK/P or PTX/P.

Abbreviations: LK, lumbrokinase; P, PEG-b-(PELG-g-(PZLL-r-PLL)); PEG-b-(PELGg-(PZLL-r-PLL)), poly(ethylene glycol)-b-(poly(ethylenediamine L-glutamate)-g-poly (ع-benzyoxycarbonyl-L-lysine)-r-poly(L-lysine)); PTX, paclitaxel.

mechanisms of the anti-tumor effect of LK remain unknown. Some studies have shown that LK may remarkably strengthen the phagocytic functions in macrophages in the abdominal cavity of tumor-bearing rats. ${ }^{47}$ The anti-tumor effects of LK may relate to antioxidative effects and the purging of oxygen-free radicals. ${ }^{22}$ Nevertheless, the half-life of LK is very short, which limits its bioactivity. ${ }^{48}$

PTX restrains tumor growth and induces apoptosis in tumor cells. ${ }^{49,50}$ PTX is a mitotic inhibitor that has remarkable curative effects in bladder tumors. ${ }^{34}$ However, adverse side effects of PTX include gastrointestinal toxicity, hypersensitivity, neurotoxicity, and myelosuppression. ${ }^{51,52}$ The water solubility of PTX is poor, restricting its utilization and bioactivity. ${ }^{21}$

In this study, we reported a technique for increasing both the in vitro release and in vivo safety and efficacy of LK and PTX, administered as a subcutaneous abdominal injection, using a co-loading of a LK/PTX/PEG- $b$-(PELG$g$-(PZLL- $r$-PLL)) complex. In our study, we verified that PEG- $b$-(PELG- $g$-(PZLL- $r$-PLL)) can be used as a potential LK/PTX nanocarrier. ${ }^{1} \mathrm{H}$ NMR spectra and TEM showed that the synthesis proceeded in a controlled manner with successful synthesis. In addition, PEG- $b$-(PELG- $g$-(PZLL- $r$-PLL)) in J82 cells exhibited high cell viability at concentrations as high as $300 \mu \mathrm{g} / \mathrm{mL}$. In this regard, we chose PEG- $b$-(PELG$g$-(PZLL-r-PLL)) to co-load LK/PTX for sustained release to maintain its anti-tumor effect in bladder cancer. Another PEG- $b$-(PELG-g-(PZLL-r-PLL)) polymer acted as a nanocarrier and protected LK and PTX from quick degradation in rats. It augmented the efficacy and decreased the dosage and frequency of injections. In addition, PEG- $b$-(PELG- $g$-(PZLL$r$-PLL)) could improve the stable release and bioactivity of both LK and PTX in circulation.

Taken together, we found that PEG- $b$-(PELG- $g$-(PZLL$r$-PLL)) polymers prolonged the half-life and bioactivity of LK and PTX in Sprague Dawley rats. In addition, LK/PTX/ PEG- $b$-(PELG-g-(PZLL- $r$-PLL)) restrained tumor growth and induced tumor cell apoptosis.

\section{Conclusion}

This was the first study to synthesize PEG- $b$-(PELG- $g$ (PZLL-r-PLL)), which may increase the bioactivity and half-life of LK and PTX. In addition, we showed that LK, PTX, LK/PEG- $b$-(PELG- $g$-(PZLL- $r$-PLL)), PTX/PEG- $b$ (PELG- $g$-(PZLL- $r$-PLL)), and LK/PTX/PEG- $b$-(PELG- $g$ (PZLL-r-PLL)) were all capable of inhibiting bladder cancer growth and that LK/PTX/PEG- $b$-(PELG-g-(PZLL- $r$-PLL)) significantly inhibited bladder cancer growth.

\section{Abbreviations}

BLG, $\gamma$-benzyl L-glutamate; BLG-NCA, $\gamma$-benzyl L-glutamate- $N$-carboxyanhydride; bw, body weight; DDS, drug delivery system; DMF, $N, N$-dimethylformamide; HPLC, high-performance liquid chromatography; ${ }^{1} \mathrm{H}$ NMR, ${ }^{1} \mathrm{H}$ nuclear magnetic resonance spectroscopy; ICMJE, International Committee of Medical Journal Editors; LK, lumbrokinase; MNU, methylnitrosourea; MTT, 3-(4,5dimethylthiazol-2-yl)-2,5-diphenyltetrazolium bromide; MVD, microvessel density; MWCO, molecular weight cutoff; o.d, once a day; PBS, phosphate-buffered solution; PEG, polyethylene glycol; PEG-NH${ }_{2}$, PEG-amine; PEG- $b$-PBLG, PEG- $b$-poly ( $\gamma$-benzyl L-glutamate); PEG- $b$-PELG, PEG- $b$ poly(ethylenediamine L-glutamate); PEG- $b$-(PELG-g-PZLL), PEG- $b$-(poly(ethylenediamine L-glutamate)-g-poly( $\varepsilon$ benzyoxycarbonyl-L-lysine)); PEG- $b$-(PELG-g-(PZLL$r$-PLL)), poly(ethylene glycol)- $b$-(poly(ethylenediamine L-glutamate)-g-poly( $\varepsilon$-benzyoxycarbonyl-L-lysine)- $r$ poly(L-lysine)); PTX, paclitaxel; TEM, transmission electron microscopy; ZLL-NCA, $\varepsilon$-benzyoxycarbonylL-lysine- $N$-carboxyanhydride.

\section{Acknowledgments}

The authors greatly appreciate the editors and two anonymous peer reviewers for their critical reading and insightful comments, which have improved the manuscript substantially. This work was financially supported by the National Natural Science Foundation of China (81501043), the Science and Technology Planning Project (Laboratory Animal Project) 
of Zhejiang Province (2015C37130), and the Science and Technology Planning Project of Jiaxing (2017AY33056, 2017AY33076). The sponsors of the study were not involved in study design, data collection, data analysis, data interpretation, or writing of the manuscript.

\section{Author contributions}

BH, FT, GX and RS conceived and designed the experiments. BH, YY, FT and GX synthesized the nanocarrier. BH, YY, FT, LX, JZ and GX performed the experiments. All authors contributed toward data analysis, drafting and critically revising the paper, and agree to be accountable for all aspects of the work. All authors have read and confirmed that they meet ICMJE criteria for authorship.

\section{Disclosure}

The authors report no conflicts of interest in this work.

\section{References}

1. Siegel R, Ma J, Zou Z, Jemal A. Cancer statistics, 2014. CA Cancer J Clin. 2014;64(1):9-29.

2. Ploeg M, Aben KK, Kiemeney LA. The present and future burden of urinary bladder cancer in the world. World J Urol. 2009;27(3):289-293.

3. Du M, Shi D, Yuan L, et al. Circulating miR-497 and miR-663b in plasma are potential novel biomarkers for bladder cancer. Sci Rep. 2015;5: 10437.

4. El-Ashmawy NE, Khedr EG, El-Bahrawy HA, Al-Tantawy SM. Chemopreventive effect of omega-3 polyunsaturated fatty acids and atorvastatin in rats with bladder cancer. Tumour Biol. 2017;39(2): 1010428317692254

5. Siegel R, Naishadham D, Jemal A. Cancer statistics, 2013. CA Cancer J Clin. 2013;63(1):11-30.

6. Pan ZJ, Deng N, Zou ZH, Chen GX. The effect of curcumin on bladder tumor in rat model. Eur Rev Med Pharmacol Sci. 2017;21(4): 884-889.

7. Jemal A, Bray F, Center MM, Ferlay J, Ward E, Forman D. Global cancer statistics. CA Cancer J Clin. 2011;61(2):69-90.

8. Blaveri E, Simko JP, Korkola JE, et al. Bladder cancer outcome and subtype classification by gene expression. Clin Cancer Res. 2005;11(11): 4044-4055.

9. Sugano K, Kakizoe T. Genetic alterations in bladder cancer and their clinical applications in molecular tumor staging. Nat Clin Pract Urol. 2006;3(12):642-652.

10. Knowles MA. Molecular subtypes of bladder cancer: Jekyll and Hyde or chalk and cheese? Carcinogenesis. 2006;27(3):361-373.

11. Babjuk M, Bohle A, Burger M, et al. EAU guidelines on non-muscleinvasive urothelial carcinoma of the bladder: update 2016. Eur Urol. 2017;71(3):447-461.

12. Wirth M, Plattner VE, Gabor F. Strategies to improve drug delivery in bladder cancer therapy. Expert Opin Drug Deliv. 2009;6(7):727-744.

13. Kanemoto K, Fukuta K, Kawai N, et al. Genomic landscape of experimental bladder cancer in rodents and its application to human bladder cancer: gene amplification and potential overexpression of Cyp2a5/ CYP2A6 are associated with the invasive phenotype. PLoS One. 2016;11(11):e0167374.

14. Mansoor M, Ali S, Fasihuddin Q, Baloch MU. Superficial bladder tumours: recurrence and progression. J Coll Physicians Surg Pak. 2011; 21(3):157-160.

15. Pasin E, Josephson DY, Mitra AP, Cote RJ, Stein JP. Superficial bladder cancer: an update on etiology, molecular development, classification, and natural history. Rev Urol. 2008;10(1):31-43.
16. Herr HW. High-risk superficial bladder cancer: transurethral resection alone in selected patients with T1 tumor. Semin Urol Oncol. 1997; 15(3):142-146.

17. Liu J, Duan X. PA-MSHA induces apoptosis and suppresses metastasis by tumor associated macrophages in bladder cancer cells. Cancer Cell Int. 2017;17:76

18. Chen NC, Chyau CC, Lee YJ, Tseng HC, Chou FP. Promotion of mitotic catastrophe via activation of PTEN by paclitaxel with supplement of mulberry water extract in bladder cancer cells. Sci Rep. 2016;6:20417.

19. Zhang X, Wu Y, Zhang M, et al. Sodium cholate-enhanced polymeric micelle system for tumor-targeting delivery of paclitaxel. Int $J$ Nanomedicine. 2017;12:8779-8799.

20. Wu C, Xu J, Hao Y, et al. Application of a lipid-coated hollow calcium phosphate nanoparticle in synergistic co-delivery of doxorubicin and paclitaxel for the treatment of human lung cancer A549 cells. Int $J$ Nanomedicine. 2017;12:7979-7992.

21. Zhou M, Li X, Li Y, et al. Ascorbyl palmitate-incorporated paclitaxelloaded composite nanoparticles for synergistic anti-tumoral therapy. Drug Deliv. 2017;24(1):1230-1242.

22. Chen H, Takahashi S, Imamura M, et al. Earthworm fibrinolytic enzyme: anti-tumor activity on human hepatoma cells in vitro and in vivo. Chin Med J (Engl). 2007;120(10):898-904.

23. Tjandrawinata RR, Yunaidi DA, Susanto LW. The safety and tolerability of lumbrokinase DLBS1033 in healthy adult subjects. Drug Res (Stuttg). 2016;66(6):293-299.

24. Jiang G, Zhang W, Peng M, Yan W. [Effect of lumbrokinase on patients with acute and moderate risk pulmonary thromboembolism]. Zhong Nan Da Xие Хие Baо Yi Xиe Ban. 2017;42(10):1156-1162. Chinese.

25. Ryu GH, Park S, Kim M, Han DK, Kim YH, Min B. Antithrombogenicity of lumbrokinase-immobilized polyurethane. J Biomed Mater Res. 1994;28(9):1069-1077.

26. Alyafee YA, Alaamery M, Bawazeer S, et al. Preparation of anastrozole loaded PEG-PLA nanoparticles: evaluation of apoptotic response of breast cancer cell lines. Int J Nanomedicine. 2018;13:199-208.

27. Householder KT, DiPerna DM, Chung EP, et al. $\mathrm{pH}$ driven precipitation of quisinostat onto PLA-PEG nanoparticles enables treatment of intracranial glioblastoma. Colloids Surf B Biointerfaces. 2018;166:37-44.

28. Fichtner M, Claus C, Lessig-Owlanj J, Arnhold J, Reibetanz U. The application of LbL-microcarriers for the treatment of chronic inflammation: monitoring the impact of LbL-microcarriers on cell viability. Macromol Biosci. 2015;15(4):546-557.

29. $\mathrm{Xu} \mathrm{G}, \mathrm{Gu} \mathrm{H}, \mathrm{Hu}$ B, et al. PEG- $b$-(PELG-g-PLL) nanoparticles as TNF-alpha nanocarriers: potential cerebral ischemia/reperfusion injury therapeutic applications. Int J Nanomedicine. 2017;12:2243-2254.

30. Tong F, Zhang H. Poly (Ethylene Glycol)-Block-Brush Poly (L-Lysine) copolymer as an efficient nanocarrier for human hepatocyte growth factor with enhanced bioavailability and anti-ischemia reperfusion injury efficacy. Kidney Blood Press Res. 2017;42(3):495-508.

31. Tong F, Tang X, Luo L, et al. Sustained delivery of insulin-loaded block copolymers: potential implications on renal ischemia/reperfusion injury in diabetes mellitus. Biomed Pharmacother. 2017;91:534-545.

32. Tong F. Preparation of exenatide-loaded linear poly(ethylene glycol)brush poly(l-lysine) block copolymer: potential implications on diabetic nephropathy. Int J Nanomedicine. 2017;12:4663-4678.

33. Tong F, Tang X, Li X, Xia W, Liu D. The effect of insulin-loaded linear poly(ethylene glycol)-brush-like poly(l-lysine) block copolymer on renal ischemia/reperfusion-induced lung injury through downregulating hypoxia-inducible factor. Int J Nanomedicine. 2016;11:1717-1730.

34. Lamm DL. BCG in perspective: advances in the treatment of superficial bladder cancer. Eur Urol. 1995;27(Suppl 1):2-8.

35. Tsuji S, Chen X, Hancock B, et al. Preclinical evaluation of VAX-IP, a novel bacterial minicell-based biopharmaceutical for nonmuscle invasive bladder cancer. Mol Ther Oncolytics. 2016;3:16004.

36. McKiernan JM, Holder DD, Ghandour RA, et al. Phase II trial of intravesical nanoparticle albumin bound paclitaxel for the treatment of nonmuscle invasive urothelial carcinoma of the bladder after bacillus Calmette-Guerin treatment failure. J Urol. 2014;192(6):1633-1638. 
37. Montironi R, Cheng L, Scarpelli M, Lopez-Beltran A. Pathology and genetics: tumours of the urinary system and male genital system: clinical implications of the 4 th edition of the WHO classification and beyond. Eur Urol. 2016;70(1):120-123.

38. Guo S, Xu P, Zhou A, et al. Contrast-enhanced ultrasound differentiation between low- and high-grade bladder urothelial carcinoma and correlation with tumor microvessel density. J Ultrasound Med. 2017; 36(11):2287-2297.

39. Huang J, Ma X, Chen X, et al. Microvessel density as a prognostic factor in bladder cancer: a systematic review of literature and meta-analysis. Cancer Biomark. 2014;14(6):505-514.

40. Pustylnyak VO, Lisachev PD, Shtark MB. Expression of p53 target genes in the early phase of long-term potentiation in the rat hippocampal CA1 area. Neural Plast. 2015;2015:242158.

41. Ben Ya'acov A, Meir H, Zolotaryova L, Ilan Y, Shteyer E. Impaired liver regeneration is associated with reduced cyclin B1 in natural killer T cell-deficient mice. BMC Gastroenterol. 2017;17(1):44.

42. Hu B, Wu Y, Liu J, et al. GSK-3beta inhibitor induces expression of Nrf2/TrxR2 signaling pathway to protect against renal ischemia/ reperfusion injury in diabetic rats. Kidney Blood Press Res. 2016;41(6): 937-946.

43. Leopardo D, Cecere SC, Di Napoli M, et al. Intravesical chemoimmunotherapy in non muscle invasive bladder cancer. Eur Rev Med Pharmacol Sci. 2013;17(16):2145-2158.

44. Sindhwani P, Hampton JA, Baig MM, Keck R, Selman SH. Curcumin prevents intravesical tumor implantation of the MBT-2 tumor cell line in C3H mice. J Urol. 2001;166(4):1498-1501.
45. Jaganathan A, Murugan K, Panneerselvam C, et al. Earthworm-mediated synthesis of silver nanoparticles: a potent tool against hepatocellular carcinoma, plasmodium falciparum parasites and malaria mosquitoes. Parasitol Int. 2016;65(3):276-284.

46. Cooper EL, Ru B, Weng N. Earthworms: sources of antimicrobial and anticancer molecules. Adv Exp Med Biol. 2004;546:359-389.

47. Ville P, Roch P, Cooper EL, Masson P, Narbonne JF. PCBs increase molecular-related activities (lysozyme, antibacterial, hemolysis, proteases) but inhibit macrophage-related functions (phagocytosis, wound healing) in earthworms. J Invertebr Pathol. 1995;65(3):217-224.

48. Kasim M, Kiat AA, Rohman MS, Hanifah Y, Kiat H. Improved myocardial perfusion in stable angina pectoris by oral lumbrokinase: a pilot study. J Altern Complement Med. 2009;15(5):539-544.

49. Peltier S, Oger JM, Lagarce F, Couet W, Benoit JP. Enhanced oral paclitaxel bioavailability after administration of paclitaxel-loaded lipid nanocapsules. Pharm Res. 2006;23(6):1243-1250.

50. Parayath NN, Nehoff H, Norton SE, et al. Styrene maleic acidencapsulated paclitaxel micelles: antitumor activity and toxicity studies following oral administration in a murine orthotopic colon cancer model. Int J Nanomedicine. 2016;11:3979-3991.

51. Berveiller P, Mir O. Taxanes during pregnancy: probably safe, but still to be optimized. Oncology. 2012;83(4):239-240.

52. Pepe D, Carvalho VF, McCall M, de Lemos DP, Lopes LB. Transportan in nanocarriers improves skin localization and antitumor activity of paclitaxel. Int J Nanomedicine. 2016;11:2009-2019. 


\section{Supplementary materials Methods}

The measurement conditions of ' $\mathrm{H}$ nuclear magnetic resonance spectroscopy spectrum for poly(ethylene glycol)-b-(poly(ethylenediamine I-glutamate)-gpoly(E-benzyoxycarbonyl-I-lysine)-r-poly(I-lysine))

The freeze-dried preparation of nanoparticle poly(ethylene glycol)- $b$-(poly(ethylenediamine 1-glutamate)-g-poly( $\varepsilon$ benzyoxycarbonyl-1-lysine)-r-poly(1-lysine)) (PEG- $b$-(PELG$g$-(PZLL-r-PLL))) was dissolved in phosphate-buffered solution (PBS) ( $\mathrm{pH} 7.4)$ and oscillated at $30^{\circ} \mathrm{C}$ for $24 \mathrm{~h}$, and then was ultrasonically dissolved for $10 \mathrm{~min}$ under the $80-\mathrm{W}$ power in an ultrasonic oscillometer. ${ }^{1-5}$ Finally, the clarified nanoparticle solution was obtained to be detected by ${ }^{1} \mathrm{H}$ nuclear magnetic resonance spectroscopy, wherein the working frequency was $600 \mathrm{~Hz}$, spectrum temperature was $25^{\circ} \mathrm{C}$, the data point was $64 \mathrm{k}$, the pulse width was $30^{\circ}$, delay time was $2.1 \mathrm{~s}$, and cycle times were set at two times. ${ }^{1-3}$

\section{The concentration detection of lumbrokinase and} paclitaxel in PEG-b-(PELG-g-(PZLL-r-PLL)) and blood by high-performance liquid chromatography

The concentration detection of lumbrokinase (LK) and paclitaxel (PTX) in PEG- $b$-(PELG-g-(PZLL- $r$-PLL)) by high-performance liquid chromatography $\mathrm{y}^{6,7}$ containing 125-pump and 166-UV-detector (Beckman Coulter, Atlanta, GA, USA). Briefly, first, the parameters were set as: 1) chromatographic column: Diamond octadecylsilyl column $(250 \times 4.6 \mathrm{~mm}, 5 \mu \mathrm{m}) ; 2)$ mobile phase: methanol-5\% acetic acid (3:1);3) detection wavelength: $570 \mathrm{~nm} ; 4)$ current velocity: $1.0 \mathrm{~mL} / \mathrm{min}$; and 5) sample load: $20 \mu \mathrm{L}$. When analyzing samples under the same conditions, the standard curve (linear regression curve) of the peak area (A)-concentration (C) was drawn $(r=0.99,928)$. Furthermore, the relative standard deviations of the inter-day variability and the intra-day variability were $\leq 1.75 \%$ and $\leq 1.23 \%$, respectively, through the experiments that had been repeated three times $(\mathrm{n}=9)$. Under the experiments of loading and release of LK and PTX in PEG- $b$-(PELG- $g$-(PZLL- $r$-PLL)), within a given interval of time (at 0.02-, 0.04-, 0.08-, 0.17-, 0.33-, 0.42-, 0.5-, 0.67-, 0.75-, 1-, 1.5-, 1.67-, 1.75-, 2-, 3-, 4-, and 5-day time interval), the LK/PEG- $b$-(PELG- $g$-(PZLL$r$-PLL)), PTX/PEG- $b$-(PELG- $g$-(PZLL- $r$-PLL)), and LK/ PTX/PEG- $b$-(PELG- $g$-(PZLL- $r$-PLL)) nanocopolymers were measured accurately in a certain quantity, respectively, dissolved, constantly volumed, and centrifuged at 10,000 rpm for $15 \mathrm{~min}$ in a ultrafiltration enrichment tube (Sartorius, Shanghai, China) to obtain the liquid supernatant and to start application of sample $(20 \mu \mathrm{L})$, and finally to calculate the concentrations of free drugs based on their standard curves. The concentrations of LK and PTX in blood were detected by the same method above.

\section{LK activity test before and after loading processes}

To test the LK activity before and after loading processes, an enzyme kinetic analysis method was performed ${ }^{8,9}$ Briefly, a certain equivalent amount of free LK or the released free LK from LK/polymer was accurately weighed and dissolved in PBS (0.1 M, pH 7.4), placed in a 6-well plate and added to $3 \mathrm{~mL}$ activator containing $0.5 \mathrm{mM}$ Factor I $\alpha$ (fibrin) and $0.02 \mathrm{mM}$ tosyl-L-arginine methyl ester at $37^{\circ} \mathrm{C}$ for $10 \mathrm{~min}$. Tosyl-L-arginine methyl ester was enzyme-digested two parts: tosyl-L-arginine and methyl alcohol. The methyl alcohol was oxidized to methanal in the presence of potassium permanganate for $5 \mathrm{~min}$. Subsequently, the color reaction was presented by formaldehyde reacting with chromotropic acid in boiling water bath for $20 \mathrm{~min}$. Finally, the absorbance (OD) of per well at $574 \mathrm{~nm}$ was measured on a microplate multimode reader (Turner Biosystems, Madison, WI, USA). There was a positive correlation between the absorbance and the enzyme activity. The relative enzyme activity was calculated by comparing the OD value of LK released from the copolymer with that of free $\mathrm{LK}$, calculated as $\mathrm{OD}_{\text {realeased }} / \mathrm{OD}_{\text {free }} \times 100 \%$. The experiment was repeated 5 times. The results showed that there was no significant change in enzyme activity.

\section{References}

1. $\mathrm{Xu} \mathrm{G}, \mathrm{Gu} \mathrm{H}, \mathrm{Hu} \mathrm{B}$, et al. PEG-b-(PELG-g-PLL) nanoparticles as TNF-alpha nanocarriers: potential cerebral ischemia/reperfusion injury therapeutic applications. Int J Nanomedicine. 2017;12:2243-2254.

2. Tong F. Preparation of exenatide-loaded linear poly(ethylene glycol)brush poly(l-lysine) block copolymer: potential implications on diabetic nephropathy. Int J Nanomedicine. 2017;12:4663-4678.

3. Tong F, Tang X, Li X, Xia W, Liu D. The effect of insulin-loaded linear poly(ethylene glycol)-brush-like poly(l-lysine) block copolymer on renal ischemia/reperfusion-induced lung injury through downregulating hypoxia-inducible factor. Int J Nanomedicine. 2016;11:1717-1730.

4. Tong F, Zhang H. Poly (Ethylene Glycol)-Block-Brush Poly (L-Lysine) copolymer as an efficient nanocarrier for human hepatocyte growth factor with enhanced bioavailability and anti-ischemia reperfusion injury efficacy. Kidney Blood Press Res. 2017;42(3):495-508.

5. Tong F, Tang X, Luo L, et al. Sustained delivery of insulin-loaded block copolymers: Potential implications on renal ischemia/reperfusion injury in diabetes mellitus. Biomed Pharmacother. 2017;91:534-545.

6. Kao CW, Lee D, Wu MH, Chen JK, He HL, Liu SJ. Lidocaine/ ketorolac-loaded biodegradable nanofibrous anti-adhesive membranes that offer sustained pain relief for surgical wounds. Int J Nanomedicine. 2017;12:5893-5901.

7. Menezes PD, Frank LA, Lima BD, et al. Hesperetin-loaded lipid-core nanocapsules in polyamide: a new textile formulation for topical drug delivery. Int J Nanomedicine. 2017;12:2069-2079.

8. Jin M, Jin G, Huang W, Gao Z. PEGylation of Lumbrokinase improves pharmacokinetic profile and enhances antithrombotic effect in a rat carotid artery thrombosis model. Mol Med Rep. 2017;16(4):4909-4914.

9. John NA, Melvin IS. Methods in Enzymology. Vol 1-7. San Diego, CA, USA: Academic Press; 2011. 


\section{Publish your work in this journal}

The International Journal of Nanomedicine is an international, peerreviewed journal focusing on the application of nanotechnology in diagnostics, therapeutics, and drug delivery systems throughout the biomedical field. This journal is indexed on PubMed Central,

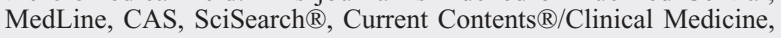

Journal Citation Reports/Science Edition, EMBase, Scopus and the Elsevier Bibliographic databases. The manuscript management system is completely online and includes a very quick and fair peer-review system, which is all easy to use. Visit http://www.dovepress.com/ testimonials.php to read real quotes from published authors.

Submit your manuscript here: http://www.dovepress.com/international-journal-of-nanomedicine-journal 